\title{
Photocatalytic Activity of Zr Doped ZnO and Its Morphology
}

\author{
Arumugam Vijayabalan ${ }^{1,2, ~ *, ~ A y y a n a r ~ S i v a k u m a r ~}{ }^{2}$, Nadarajan Suresh Babu ${ }^{3}$, \\ Arumugam Amalorpavadoss ${ }^{2}$ \\ ${ }^{1}$ Department of Chemistry, King Nandhivarman College of Arts and Science, Thellar, Kanchipuram, India \\ ${ }^{2}$ Department of Chemistry, St. Joseph's College of Arts and Science (Autonomous), Cuddalore, India \\ ${ }^{3}$ Department of Chemistry, Government College of Engineering, Thanjavur, India
}

Email address:

vijayabalanchem@gmail.com (A. Vijayabalan)

${ }^{*}$ Corresponding author

\section{To cite this article:}

Arumugam Vijayabalan, Ayyanar Sivakumar, Nadarajan Suresh Babu, Arumugam Amalorpavadoss. Photocatalytic Activity of Zr Doped $\mathrm{ZnO}$ and its Morphology. International Journal of Bioorganic Chemistry. Vol. 4, No. 1, 2019, pp. 14-18. doi: 10.11648/j.ijbc.20190401.13

Received: February 3, 2019; Accepted: March 8, 2019; Published: March 30, 2019

\begin{abstract}
Doped $\mathrm{ZnO}$ with $\mathrm{Zr}$ has been obtained by sol-gel method and characterized by powder X-ray diffraction, energy dispersive X-ray spectrum, Scanning electron micrographs, and UV-visible diffuse reflectance and photoluminescence spectroscopy. Powder XRD shows that synthesized $\mathrm{Zr}$ doped $\mathrm{ZnO}$ has hexagonal wurtzite structure and high crystallinity, DRS reveals that wavelength are shifted from UV region to visible region when Zr doping. PL spectra clearly reveal that the recombinations of electron-hole pair in $\mathrm{ZnO}$ are suppressed by $\mathrm{Zr}$ doping. $\mathrm{Zr}$-doping enhances the photocatalytic degradation of methylene blue dye than $\mathrm{ZnO}$ under visible light.
\end{abstract}

Keywords: Sol-gel Method, Zr-ZnO, Visible Light, Methylene Blue Dye

\section{Introduction}

In recent years, many researchers are discovered the new and modified semiconductor materials and application of these materials is cleaning the toxic effluents. $\mathrm{ZnO}$ photocatalyst is 3.2 $\mathrm{eV}$ and high photoactivity in $\mathrm{UV}$ spectrum [1]. $\mathrm{ZnO}$ photocatalyst are used in luminescence, optics, optoelectronics, sensors, actuators, energy, biomedical sciences, and spintronics. $\mathrm{ZnO}$ has been used as a photocatalyst, owing to its high activity, low cost and friendly environment. However, the problem of $\mathrm{ZnO}$ is the high recombination rate of electron-hole pair, resulting in low degradation efficiencies of the organic pollutants. To overcome these limitations, a number of strategies have been adopted to improve the charge separation efficiency and then enhance the photocatalytic activity of the catalyst such as the Semiconductors doping or hybridizing. $\mathrm{ZnO}$ modified with FeOsemiconductor [2]. To study the influences of $\mathrm{Zr}$-doped $\mathrm{ZnO}$ and nanosized $\mathrm{ZrO} 2$ system structure and photocatalytic performance and ultrasoftpseudopotential method also influence ZnOstructure [3-5]. Effect of Zrdoping andZr-Al co doping on the electrical andoptical properties of $\mathrm{ZnO}[6,7]$. Report that the grain size of $\mathrm{Zr}$-doped $\mathrm{ZnO}$ is small and the surface area is high. Also within $0.2-1 \mathrm{at} \% \mathrm{Zr}$-doping, the higher the doping amount is, the stronger the photocatalytic activity [8]. Utilized sol-gel method to study the influences of $\mathrm{Zr}$-doping on $\mathrm{ZnO}$ photoelectric properties. The results showed that when $\mathrm{Zr}$ doping fell in $0-5 \mathrm{at} \%$, the resistances of all the doping systems all were greater than that of pure $\mathrm{ZnO}$. Moreover, when the doping amount was $3 \mathrm{at} \%$, the transmissivity of the doping system was the most ideal. Kim et al. to study the photoelectric property of $\mathrm{Zr}$-doped $\mathrm{ZnO}$ system by using pulse laser deposition method [9]. The results indicate that the higher the oxygen pressure is, the greater the doping system resistance is and the higher the transmissivity. Many methods are reported as synthesize coupled metal oxides are photo-deposition method [10] solid state dispersion method [11] hydrothermal method [12] impregnation method [13, 10], sol-gel method [14], coprecipitation method [15-17] mechanical mixing method [18], flame spray pyrolysis [19] and microwave synthesis. [20].

The present paper reports the environmental friendly greener synthesis of novel Zr-doped ZnOusing sol-gel synthesis and investigations on its photocatalytic activity 
under visible light for the degradation of MB dye.

\section{Materials and Methods}

\subsection{Materials}

$\mathrm{Zr}\left(\mathrm{NO}_{3}\right)_{3}$ (Loba-chemi), $\mathrm{Zn}\left(\mathrm{NO}_{3}\right)_{2}$ (Loba-chemi), Methylene blue dye(Merck) and liquid ammonia(Qualigens) were used. Distilled water is used for the makeup solution.

\subsection{Methods}

Preparation of $\mathrm{Zr}-\mathrm{ZnO}$ by Sol-gel method

To appropriate concentration of $\mathrm{Zn}\left(\mathrm{NO}_{3}\right)_{2}$ and $\mathrm{Zr}\left(\mathrm{NO}_{3}\right)_{3}$ solution was added under stirring. After 1:1 aqueous ammonia solution was added to reach a $\mathrm{pH} 9.5$ under continuous stirring. The crystals were collected by filtration, dried and calcined at $500^{\circ} \mathrm{C}$ for $1 \mathrm{~h}$ in a muffle furnace fitted with a PID temperature controller. The heating rate was $10^{\circ} \mathrm{C}$ $\mathrm{min}^{-1}$. The undoped $\mathrm{ZnO}$ crystals were synthesized by adopting the same procedure but without $\mathrm{Zr}\left(\mathrm{NO}_{3}\right)_{3}$. The chemicals used were of analytical grade and deionized distilled water was employed for the experiments.

\subsection{Characterization Techniques}

A PANalyticalX'Pert PRO diffractometer with $\mathrm{Cu}$ Ka rays of $1.5406 \AA$ was employed to record the powder X-ray diffractograms (XRD) of the samples at $40 \mathrm{kV}$ and $30 \mathrm{~mA}$ with a scan rate of $0.04^{\circ} \mathrm{s}^{-1}$ in a $2 \theta$ range of $10-75^{\circ}$. The morphologies of $\mathrm{Zr}$-doped $\mathrm{ZnO}$ and $\mathrm{ZnO}$ synthesized by solgel method were assessed using a JSM6610 model scanning electron microscope (SEM) under vacuum mode. The energy dispersive X-ray (EDX) spectrum was obtained using the Oxford instruments attached to scanning electron microscope (SEM). The diffuse reflectance spectra were obtained with a PerkinElmer Lamda 35 spectrometer. A PerkinElmer LS 55 fluorescence spectrometer was used to record the photoluminescence (PL) spectra at room temperature.

\subsection{Photocatalytic Activity}

The visible light photocatalytic studies were made in an immersion type photo reactor equipped with a 150-W tungsten halogen lamp fitted into a double walled borosilicate immersion well of $40 \mathrm{~mm}$ outer diameter with inlet and outlet for circulation of $\mathrm{K}_{2} \mathrm{Cr}_{2} \mathrm{O}_{7}$ solution. The $1 \mathrm{~N} \mathrm{~K}_{2} \mathrm{Cr}_{2} \mathrm{O}_{7}$ solution used removes $99 \%$ of the UV light with wavelength between 320 and $400 \mathrm{~nm}$ and acts as a UV cutoff filter. After the addition of the catalyst to the dye solution, air was bubbled through the solution which kept the catalyst particles under suspension and at constant motion. The catalyst was separated after the illumination. The dye Methylene blue was analyzed spectrophotometrically at $656 \mathrm{~nm}$.

\section{Results and Discussion}

\subsection{Crystal Structure and Morphology}

The energy dispersive X-ray diffraction spectrum of $\mathrm{Zr}$ $\mathrm{ZnO}$ is shown in figure 1 . It is reveals that $\mathrm{Zr}, \mathrm{Zn}$ and $\mathrm{O}$ element. It is concluding that $1.83 \% \mathrm{Zr}$ doped $\mathrm{ZnO}$ lattice. Figure 2. Shows that the scanning electron microscope image of $\mathrm{Zr}-\mathrm{ZnO}$ particles. It is shows that hexagonal structures of $\mathrm{ZnO}$ are destroyed with doped $\mathrm{Zr}^{3+}$ ion. It is also confirms that doped $\mathrm{ZnO}$ as micron size.

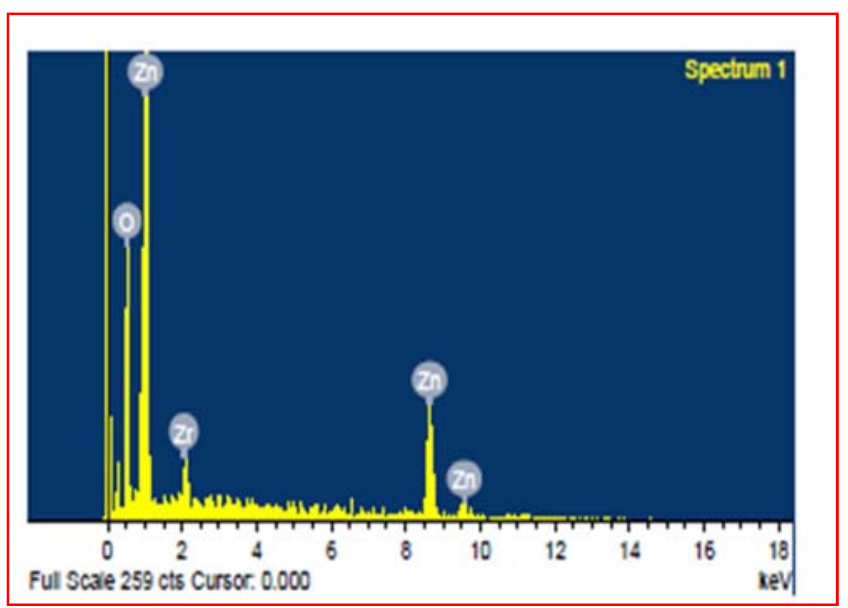

Figure 1. Energy dispersive $X$-ray spectrumof $\mathrm{Zr}$ - ZnO.

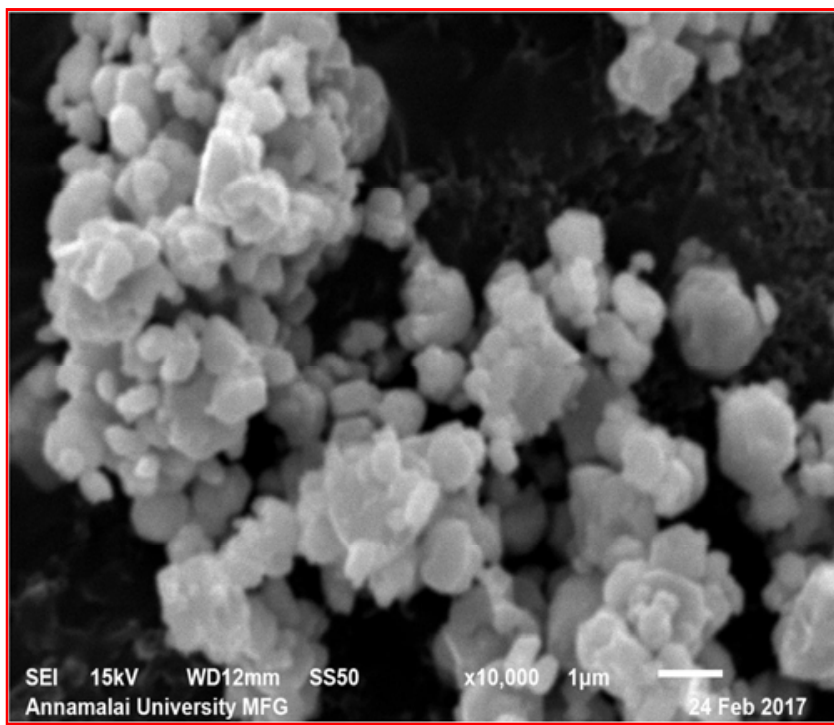

Figure 2. SEM images of $Z r-Z n O$.

The powder X-ray diffraction spectra of $\mathrm{ZnO}$ and $\mathrm{Zr}-\mathrm{ZnO}$ are shown in figure 3 . For bare $\mathrm{ZnO}$, the diffraction peaks are located at $2 \theta=31.737,34.379,36.215,47.484,56.536$, $62.777,66.304,67.868$, and 69.009 are associated with [100], [002], [101], [102], [110], [103], [200], [112] and [201] planes respectively. This pattern has been indexed as hexagonal wurtzite phase of $\mathrm{ZnO}$ with lattice constants $\mathrm{a}=\mathrm{b}=0.324 \mathrm{~nm}$ and $\mathrm{c}=0.521 \mathrm{~nm}$ (JPCDS card number: 891397), and further it is also confirmed that the synthesized catalyst is free of impurities as it does not contain any characteristic XRD peaks other than $\mathrm{ZnO}$ peaks. Sol-gel synthesized $\mathrm{Zr}-\mathrm{ZnO}$ diffraction pattern totally match with bare $\mathrm{ZnO}$ pattern. Further, the absence of cubic phase of $\mathrm{ZrO}_{2}$ peak at $2 \theta$ value is $30.30,35.40,50.60,59.8,62.85^{\circ}$ (JCPDS card no: 27-0997), monoclinic (JCPDS no 37-1484) and 
tetragonal phase (JCPDS no: 86-0965) of $\mathrm{ZrO}_{2}$ are absent in $\mathrm{Zr}-\mathrm{ZnO}$ catalyst. Sharp diffraction peaks indicate that the samples have high crystallinity. The average particle size (D) is calculated by using the Debye-Scherrer's equation $D=$ $0.9 \lambda / \beta \cos \theta$. Where, $\lambda$ is the $\mathrm{X}$-ray wavelength of $1.54 \AA, \beta$ is the full-width at half maximum, $\theta$ is the Bragg's diffraction angle and surface area calculated by $S=6 / \rho D$, where $S$ is the specific surface area, $D$ is the average particle size and $\rho$ is the material density. From the table-1, the crystal size of bare $\mathrm{ZnO}$ and $\mathrm{Zr}-\mathrm{ZnO}$ are 10.06 and $12.16 \mathrm{~nm}$ corresponding surface area is 105.2 and $73.08 \mathrm{~m}^{2} \mathrm{~g}^{-1}$ respectively. It is also shows that the average particles size no change with $\mathrm{Zr}$ doped compare to bare $\mathrm{ZnO}$.

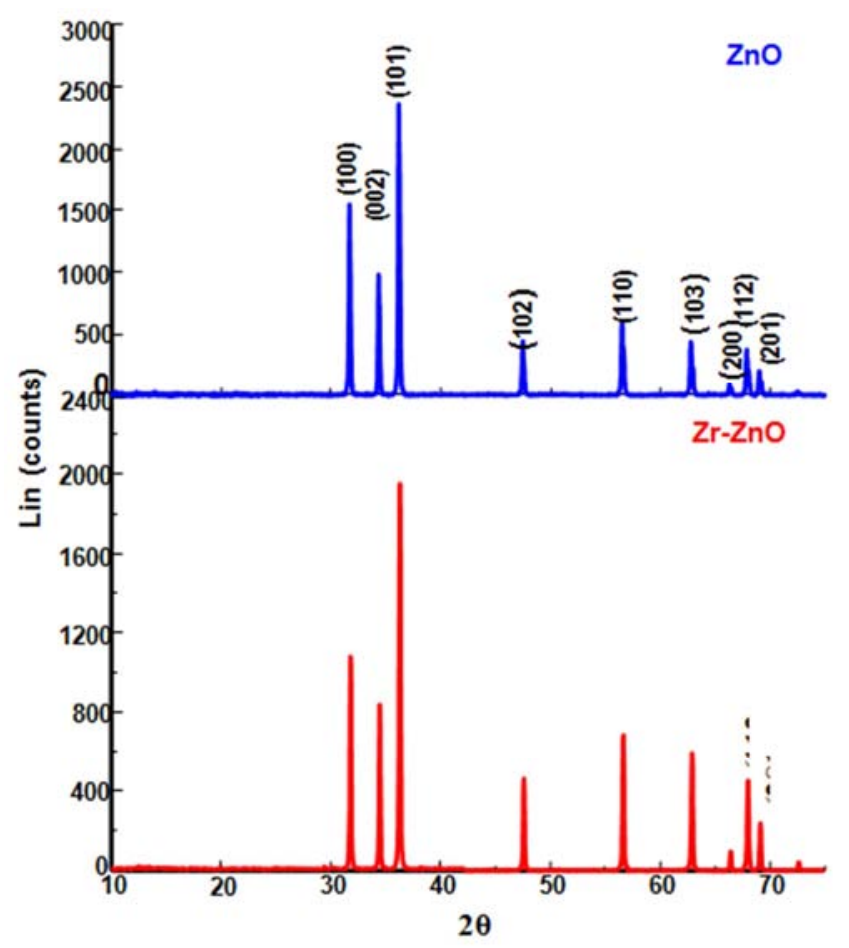

Figure 3. Powder X-ray diffraction spectrum of $\mathrm{Zr}$ - $\mathrm{ZnO}$ and $\mathrm{ZnO}$.

Table 1. Crystal size (D) and Surface area (S) of $\mathrm{ZnO}$ and $\mathrm{Zr}$ - ZnO.

\begin{tabular}{lll}
\hline Oxide & $\boldsymbol{D}, \mathbf{n m}$ & $\boldsymbol{S}, \mathbf{~ m}^{\mathbf{2}} \mathbf{g}^{\mathbf{1}}$ \\
\hline $\mathrm{ZnO}$ & 10.08 & 105.2 \\
$\mathrm{Zr}-\mathrm{ZnO}$ & 12.16 & 73.08 \\
\hline
\end{tabular}

\subsection{Band Gap Energy}

The diffuse reflectance spectrum of $\mathrm{Zr}-\mathrm{ZnO}$ are shown in figure 4. In $\mathrm{Zr}-\mathrm{ZnO}$ particles has higher absorption in visible region compare to bare $\mathrm{ZnO}$ (not shown in figure). To calculate the band gap energies of $\mathrm{Zr}-\mathrm{ZnO}$ catalysts, UV-vis spectra in the diffuse reflectance mode $(\mathrm{R})$ were transformed to the Kubelka-Munk function $F(R)$ to separate the extent of light absorption from scattering. The direct band gap energies of $\mathrm{Zr}-\mathrm{ZnO}$ catalysts was obtained from the plot of the modified Kubelka-Munk function $[F(R) E]^{2.0}$ versus the energy of the absorbed light $\mathrm{E}$ are shown in figure 5 The direct band gap energy of $\mathrm{Zr}-\mathrm{ZnO}$ particles is $3.02 \mathrm{eV}$.

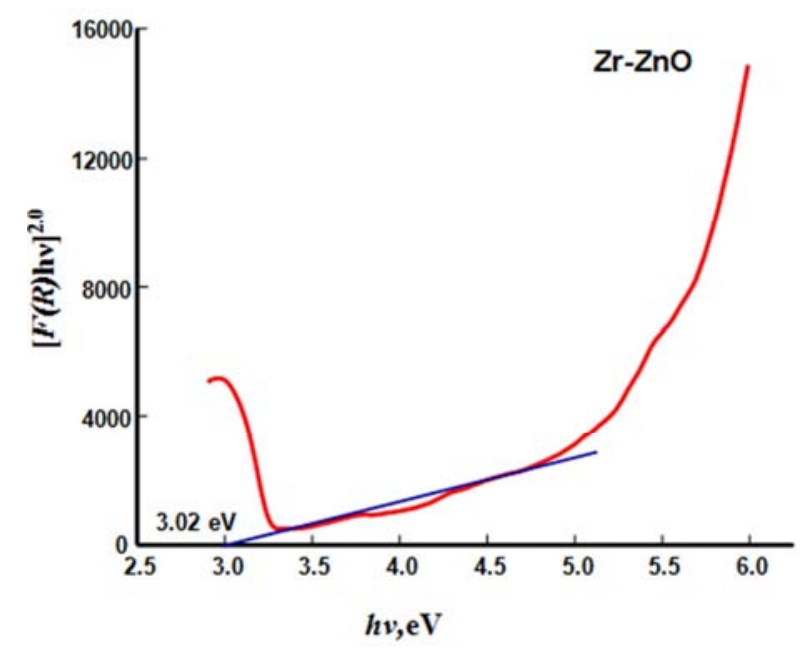

Figure 4. Tauc plot for direct band gap energy of $\mathrm{Zr}-\mathrm{ZnO}$.

\subsection{Photoluminescence}

The photoluminescence (PL) spectra of the bare $\mathrm{ZnO}$ and $\mathrm{Zr}-\mathrm{ZnO}$, are shown in figure 5 and figure 6 respectively. Photoluminescence occurs due to the recombination of electron-hole pair in the semiconductor. The loading $\mathrm{Zr}$ with $\mathrm{ZnO}$ does not shift the emission of $\mathrm{ZnO}$, but the intensity of $\mathrm{PL}$ emission decreases when compared to bare $\mathrm{ZnO}$. The trapping of photogenerated electron by $\mathrm{Zr}$ reduces the electron-hole recombination leading to the decrease of PL emission. This decrease in the rate of electron-hole recombination enhanced the photocatalytic activity of $\mathrm{ZnO}$.

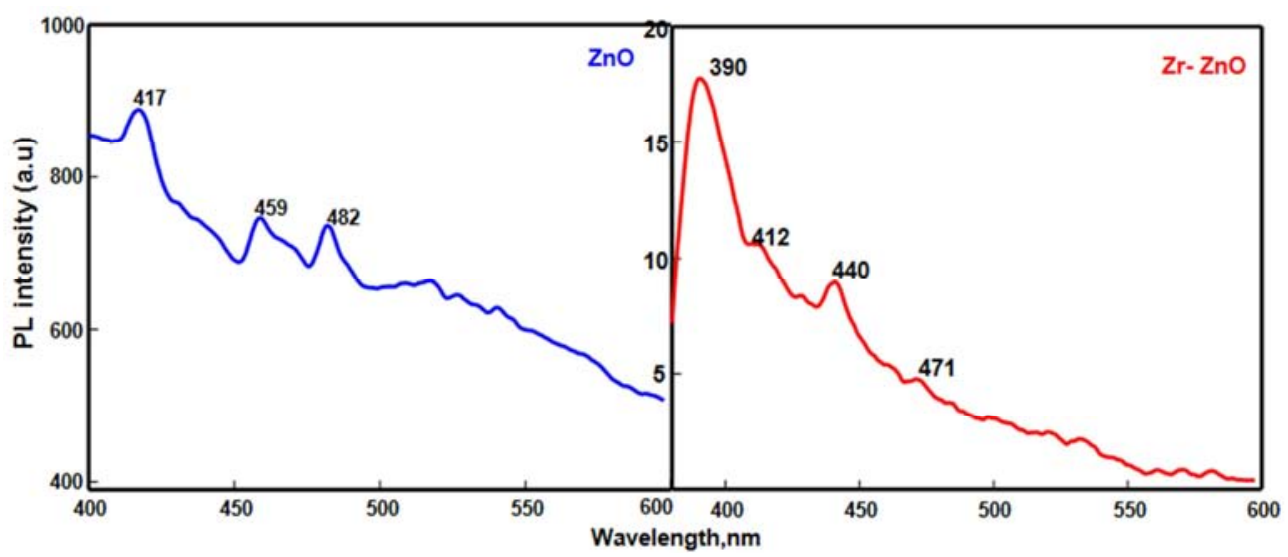

Figure 5. Photoluminescence spectra of $\mathrm{ZnO}$ and $\mathrm{Zr}$ doped $\mathrm{ZnO}$. 


\subsection{Dye Degradation}

The temporal profiles degradation of methylene blue dye under visible light is shown in figure 6 . It is noted that the $58 \%$ (remaining $4.5 \mathrm{ppm}$ dye solution) degradation is observed for $\mathrm{Zr}-\mathrm{ZnO}$ in $180 \mathrm{~min}$. whereas ZnOdegrade $41 \%$ (remaining $6.2 \mathrm{ppm}$ dye solution) in $180 \mathrm{~min}$. This might be due to trapping photo-excited electrons at conduction band by decreasing the electron-hole recombination as a consequence of $\mathrm{Zr}$ dopant into $\mathrm{ZnO}$ environment. Doping has regulated the degradation occurred by exhibiting the highest photo catalytic degradation efficiency in methylene blue dye This is because the incorporated $\mathrm{Zr}$ atom acts as electron traps by suppressing the recombination of photo-generated holes and electrons.

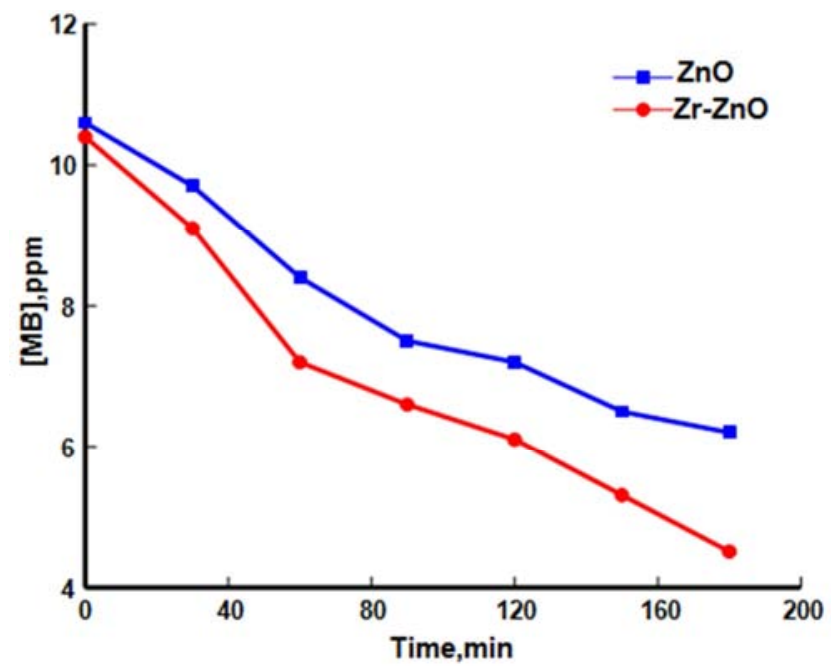

Figure 6. Temporal profiles of degradation of methylene blue dye under Visible light.

\section{Conclusions}

The $\approx 2 \% \mathrm{Zr}$ doped $\mathrm{ZnO}$ was prepared by sol-gel method. $\mathrm{XRD}$ reveals that prepared $\mathrm{Zr}$ doped $\mathrm{ZnO}$ as hexagonal wurtzite structure and absence of $\mathrm{Zr}^{3+}$ ion peak in $\mathrm{ZnO}$ crystals. SEM images shows the prepared doped $\mathrm{ZnO}$ micron in size and destroy the hexagonal wurtzite structure of $\mathrm{ZnO}$ with addition of $\mathrm{Zr}^{3+}$ ion, EDX confirms the presence of $\mathrm{Zr}^{3+}$ ion in $\mathrm{ZnO}$ crystals, DRS spectrum confirms the direct band gap energy of $\mathrm{Zr}$ doped $\mathrm{ZnO}$ is $3.02 \mathrm{eV}$. $\mathrm{Zr}^{3+}$ ion does not shift the emission of $\mathrm{ZnO}$, but the intensity of $\mathrm{PL}$ emission decreases when compared to bare $\mathrm{ZnO}$. $\mathrm{Zr}$ doped $\mathrm{ZnO}$ is more enhanced photocatalytic degradation of methylene blue dye than bare $\mathrm{ZnO}$ under visible light.

\section{References}

[1] S. M. Lama., J. A. Queka., J. C. Sin. Mechanistic investigation of visible light responsive $\mathrm{Ag} / \mathrm{ZnO}$ micro/ nanoflowers for enhanced photocatalytic performance and antibacterial activity, J. of Photochem. Photobiol., A: Chem., vol. 353, pp. 171-184, 2018.
[2] O. Bechambi., M. Chalbi., W. Najjara. and S. Sayadi., Photocatalytic activity of $\mathrm{ZnO}$ doped with $\mathrm{Ag}$ on the degradation of endocrine disrupting under UV irradiation and the investigation of its antibacterial activity, applied surface science, http://dx.doi.org/doi:10.1016/j.apsusc.2015.03.049.

[3] S. N. Basahel., Tarek T Ali, M. Mokhtar. and K. Narasimharao., Influence of crystal structure of nanosized $\mathrm{ZrO}_{2}$ on photocatalytic degradation of methyl orange, Nano. Res. Lett., DOI 10.1186/s11671-015-0780-z.

[4] N. C. S. Selvam., J. J. Vijaya., L. J. Kennedy., Effects of Morphology and $\mathrm{Zr}$ Doping on Structural, Optical, and Photocatalytic Properties of $\mathrm{ZnO}$ Nanostructures, Ind. Eng. Chem. Res. Vol. 51, pp. 16333, 2012.

[5] F. G. Wang., M. S. Lv., Z. Y. Pang., T. L. Yang., Y. Dai., S. H. Han., Theoretical study of structural, optical and electrical properties of zirconium-doped zinc oxide, Appl. Surf. Sci. vol. 254, pp. 6983, 2008.

[6] Q. Hou. C. Zhao., Z. Xu., Effect of Zr doping on the electrical and optical properties of $\mathrm{ZnO}$, Chem Phys. Lett., http://dx.doi.org/10.1016/j.cplett.2016.06.075.

[7] J. H. Luo. Q. Liu., L. N Yang., Z. Z. Sun., Z. S. Li., Firstprinciples study of electronic structure and optical properties of ( $\mathrm{Zr}-\mathrm{Al})$-codoped $\mathrm{ZnO}$, Comp. Mater. Sci., vol.82, pp. 70, 2014.

[8] C. Y. Tsay., K. S. Fan., Optimization of Zr-doped ZnO thin films prepared by sol-gel method, Mater. Trans., vol. 49, pp. 1900, 2008.

[9] H. Kim., J. S. Horwitz., W. H. Kim., S. B. Qadri., Z. H. Kafafi., Anode material based on $\mathrm{Zr}$-doped $\mathrm{ZnO}$ thin films for organic light-emitting diodes, Appl. Phys. Lett., vol. 83, pp. 3809, 2003.

[10] P. Sathishkumar. R. Sweena. W. Jerry. S. Anandan, Synthesis of $\mathrm{CuO}-\mathrm{ZnO}$ nanophotocatalyst for visible light assisted degradation of a textile dye in aqueous solution, J. Chem. Eng., vol. 171, pp. 136-140, 2011.

[11] A. Kambur., G. S Pozan., I. Boz. Preparation, characterization and photocatalytic activity of $\mathrm{TiO}_{2}-\mathrm{ZrO}_{2}$ binary oxide nanoparticles, Appl. Catal. B: Environ. vol. 115, pp. 149-158, 2012.

[12] W. Liao, T. Zheng. P. Wang., S. Tu., W. Pan., Efficient microwave-assisted photocatalytic degradation of endocrine disruptordimethylphthalate over composite catalys $\mathrm{ZrOx} / \mathrm{ZnO}$, J. Environ. Sci. vol. 22, pp. 1800-1806, 2010.

[13] J. C. Tristao., F. Magalhaes., P. Corio. M. T. C. Sansiviero. Electronic characterization and photocatalytic properties of $\mathrm{CdS} / \mathrm{TiO}_{2}$ semiconductor composite, J. Photochem. Photobiol. A: Chem., vol. 181, pp. 152-157, 2006.

[14] B. Neppolian., Wang, H. Yamashita., H. Choi., Synthesis and characterization of $\mathrm{ZrO}_{2}-\mathrm{TiO}_{2}$ binary oxide semiconductor nanoparticles: application and interparticle electron transfer process, Appl. Catal. A, vol. 333, pp. 264-271, 2007.

[15] H. Zou. Y. S Lin., Structural and surface chemical properties of sol-gel derived $\mathrm{TiO}_{2}-\mathrm{ZrO}_{2}$ oxides, Appl. Catal. A: Gen., vol. 265, pp. 35-42, 2004.

[16] H. Wang. S. Baek. J. Lee. S. Lim. High photocatalytic activity of silver- loaded $\mathrm{ZnO}-\mathrm{SnO}_{2}$ coupled catalysts, Chem. Eng. J. vol. 146, pp. 355-361, 2009. 
[17] K. Vignesh., R. Priyanka., M. Rajarajan. A. Suganthi., Photo reduction of $\mathrm{Cr}$ (VI) in water using $\mathrm{Bi}_{2} \mathrm{O}_{3}-\mathrm{ZrO}_{2}$ nanocomposite under visible light irradiation, Mater. Sci. Eng. B, vol. 178, pp 149-157, 2013.

[18] W. Zheng. Z. Bingru. L. I. Fengting., A simple and cheap method for preparation of coupled $\mathrm{ZrO}_{2} / \mathrm{ZnO}$ with high photocatalytic activities, Front. Environ. Sci. Eng. China. vol 1, pp. 454-458, 2007.

[19] C. Chaisuk. A. Wehatoranawee. S. Preampiyawat. S. Netiphat.
A. Shotipruk. J. Panpranot, B. Jongsomjit. O. Mekasuwandumrong. Preparation and characterization of $\mathrm{CeO}_{2} / \mathrm{TiO}_{2}$ nanoparticles by flame spray pyrolysis, Ceram. Int. vol. 37, pp. 1459-1463, 2011.

[20] E. D, Sherly. J. Judith Vijaya. N. ClamentSagayaSelvam. L. JohnKennedy. Microwave assisted combustion synthesis of coupled $\mathrm{ZnO}-\mathrm{ZrO}_{2}$ nanoparticles and their role in the photocatalytic degradation of 2, 4-dichlorophenol, Ceram. Inter., vol. 40, pp 5681-5691, 2014. 